\title{
The Academic Discipline of Tropical Surgery
}

\author{
Michael H. Cotton
}

Published online: 7 July 2010

(C) Société Internationale de Chirurgie 2010

Over 2 billion people, more than a third of the world's population, live in the tropics and sub-tropics. In most of the countries of these regions, the risks of injury or death from trauma is hugely greater than in the affluent West. Furthermore, obtaining surgery for eminently curable conditions is difficult, expensive, and often hazardous. An estimate has been given that approximately $11 \%$ of the global burden of disease is surgically treatable [1].

Simple procedures that could transform a young person's life (for example, club foot manipulation or even simple childhood inguinal herniotomy) have the potential, at minimal cost, of transforming a life. To change a young person's crippled existence to full participation in society has the cost-benefit potential of decades rather than years or months.

Such analysis appears self-evident for many healthcare workers with first-hand experience in resource-poor countries. Twenty years as a general surgeon in Zimbabwe made this abundantly clear to me. Policy makers, however, do need statistics, and it is a welcome sign that more and more data are emerging to demonstrate that surgery is indeed cost-effective.

The World Health Organization (WHO) has recognized the need to roll out surgery for the masses in the developing world [2], noting en passant the dire consequences of trauma, which has reached almost epidemic proportions in many places. Trauma remains largely maltreated or untreated. Its effective treatment is, by definition, surgical. Until recently, surgery was considered an expensive luxury

M. H. Cotton $(\varangle)$

Service de Chirurgie Viscérale, Centre Hospitalier Universitaire Vaudois, 1011 Lausanne, Switzerland

e-mail: mikeytha@gmail.com for enthusiasts, but major improvements in care have been shown to be achievable without huge cost inputs [3].

Real medical impact in the tropics was initially sought by dealing with global problems of gastroenteritis, malaria, malnutrition, and, more recently, human immunodeficiency virus (HIV). Immunization programs removed poliomyelitis from the world scene; spraying limited the advance of malaria, and many exotic tropical diseases once endemic have been virtually eliminated. The World Health Organization introduced its highly effective essential drugs program and the World Bank launched its essential clinical package. A Caesarean section is the only surgical intervention within this package, and it remains the commonest necessary surgical procedure worldwide. Nonetheless it is becoming manifestly apparent that a basic list of surgical procedures could be drawn up that would cater to the needs of $90 \%$ of cases. The skills of a senior specialized surgeon have been shown in one study to be unnecessary in $86.4 \%$ of cases [4].

However, the attitude toward surgery is changing. We may call this surgery for the under-resourced 2 billion of the world "Tropical Surgery," for want of a better term. But who will direct this new focus on Tropical Surgery? Who will direct its path? Where will the surgeons for the WHO recommendations, for example, for circumcision to diminish the incidence of HIV disease, be found and trained?

Training programs in many countries are wedded to oldfashioned Western models that are now inadequate to deal with the exigencies of the demand. The pursuit of specialization leads to well-qualified experts willing only to practice in specifically equipped centers of excellence, usually in private practice. Their contribution to the global surgical need is minimal, and yet they cost their countries vast sums in terms of educational input. Initiatives, such as 
surgical camps, specialist outreach, and decentralization of surgical services, aim to push surgeons out of cities into the rural districts [5], but these represent top-down rather than bottom-up strategies. In reality, the result is an obscene mix of high-technology surgery for the rich and practically none for the poor, even within the mega-metropolises of the world.

It is a sine qua non that the long-term solution to alleviating the global burden of surgical disease lies in building up a domestic surgical workforce capable of responding to the major causes of surgically related morbidity and mortality [6]. However well-meaning or well-funded, the armies of volunteers or short-term expatriates will only provide a stop-gap, and they may cause more problems than they allieviate [7]. They remain hopelessly disconnected and individualistic.

Training for basic surgery needs to include non-physicians [8], must include basic anesthesiology, and has to concentrate on the essentials of surgical practice. These fundamentals must be co-ordinated with the perceived needs in order to equip a series of frontline doctors able to stand in the breach. Such training needs to be streamlined and speeded up [9], and this is the primary urgent task of an academic discipline of Tropical Surgery.

Academic institutes of tropical medicine, which have been established for many years in different parts of the globe, have made excellent contributions and have had an unmeasurable influence worldwide. However, despite their effectiveness, the personnel of such institutes generally do not have the resources, time, or expertise to devote themselves to topics related to surgery.

Moreover, academic centers in the tropics are themselves struggling against the odds, and have, like their clinical counterparts, been left behind in the advancing technological and electronic age. Thus a disparate group of surgeons, frequently struggling with a lack of resources, certainly without sophisticated secretarial assistance, and always without much funding, is left to contribute to the world's understanding of surgery in the greater part of the globe. They have formed individual groups, and much like the volunteers and expatriates, and often in combination with them, do their bit in an uncoordinated fashion.

What does this type of surgery involve? What does it cost ? Is it, in reality, any different from surgery in the West? Is it merely surgery practiced in a more exotic environment, with perhaps some esoteric conditions, and maybe in unusual surroundings? Surely a hernia remains a hernia whether in Birmingham or in Birmitrapur.

The ramifications of surgical practice in the tropics are, indeed, various and varied, as has been shown by Welling et al. in their description of the sins of humanitarian medicine [10]. Facilities are often basic, technological help scarce, financial means limited, and time at a premium.
Surgeons may have to operate with minimally trained assistants, they may have to perform procedures with which they are not fully conversant, and they may have to perform some basic anesthesia without a trained anesthesiologist; they will always have to improvise [11].

Does this mean that such surgical practice is a priori substandard? Surely not, if proper instruction can be made available and a methodology can be introduced that takes cognizance of the situation as it exists in practice on the ground. Surgery must be done with what is to hand, and not to be deemed impossible just because some advanced gadgetry is not available [12]. Great improvements in trauma can be achieved with minimal financial and technological input.

The results will be the measure by which standards can be set. But where are the data on results? Unfortunately, most surgery that is done is not submitted to any kind of analysis [13]. This means, of course, that there is practically no information about the suitability and efficacy of much surgery that is done in the tropics. However, much amazing and brilliant work is done in adverse circumstances. The lessons learned are, however, by and large, never disseminated to a global audience. Furthermore, when a new technique appears, for example the Lichtenstein mesh hernia repair, there are no data to support its applicability compared with other methods. Nonetheless, it is frequently religiously recommended as a new gold standard for the tropics because it has been deemed so in the West. Is this good practice? Is it good logic? Is this a sort of medical imperialism? Is it indeed realistic?

An enormous amount of surgical data awaits analysis in the tropics: the amount of pathology is so huge, and so diverse, that theses galore are waiting to be written with the material available. But, at present, this vast resource is not being utilized [14]. Little surgical research emerges from the tropics, and what is written is often side-lined, or considered of esoteric relevance only. For example, much information about surgical tuberculosis or HIV published in learned peer-reviewed Western journals is based on analysis of small numbers of patients and is therefore of dubious significance. Yet there exists in the tropics a treasure trove at least as fantastic and rich as the contents of Tutankhamen's tomb.

Of course, Tropical Surgery can also and must include the treatment of specifically tropical diseases, such as schistosomiasis, ascariasis, Chagas' disease, and leishmaniasis, among others; but the subject desperately needs to encompass how to cope with surgical patients in their own environment. The impact on surgery of widespread tropical conditions, such as sickle cell disease, or anemias of various kinds, quite apart from general malnutrition or the whole panoply of HIV disease, has also to be analyzed and understood. 
In fact, surgery among a cohort of patients with HIV disease is a vastly underexamined subject. Clinical research has concentrated on the HIV-related conditions that may present to the surgeon, the risks of clinical exposure, and of course the effects of anti-retroviral therapy. However, experience of those in the field shows that non-HIV-related conditions appearing in untreated HIV-affected individuals, such as appendicitis or peritonitis for example, present often quite bizarrely, and many of the traditional parameters of diagnosis are simply not present. Though these facts may be known to many who have gained considerable experience working in areas where HIV disease is rife, their expertise is not widely disseminated.

Through basic grounding in essential surgery, the tropical surgeon inevitably becomes a jack of many trades. This need not mean that tropical surgeons are masters of none; indeed, their very generality enables them treat their patients as whole persons, and as a result they can adopt a holistic approach to practice much more easily than their Western counterparts $[15,16]$. Anyway, Tropical Surgery inevitably encompasses a very general field, including gynecology and obstetrics. In these fields, par excellence, the place of procedures almost forgotten in the West, such as symphysiotomy, uterine surgery using a cervical tourniquet, or vesciovaginal fistula repair, may be properly evaluated.

Is then global surgery just for the enthusiast or the WHO? Quite apart from the moral imperative, there is a huge amount of knowledge and experience to be gained by crosspollination of ideas and practice. The West must rid itself of the paternalistic notion that it knows best, and in humility learn from those who may actually know more but have less.

All too frequently surgical teams are dispatched to farflung parts of the world to deal with consequences of disasters, natural or man-made; these teams obviously need to be briefed about conditions on the ground, and the medical environment in which they will find themselves, quite apart from the sociopolitical background that exists. Even with all their modern equipment transported to the scene, emergency teams will always have to improvise, and for this they need the experience of the tropical surgeon. They will often, just like the surgeon working up-country on his own, have little access to immediate laboratory back-up, and so will need to know how to evaluate fluid and blood deficits accurately by clinical estimation alone. For this, they will need clinical instruction from those who have had to work in such situations. They also need to be prepared to work "outside their own box." Indeed, as an orthopedic surgeon found when flown out from the West to deal with tsunami victims in Indonesia in 2005, his first (and most important) necessary surgical intervention was a Caesarean section! (Mannion, personal communication, 2005), something for which he needed an instruction manual [17].
Training and research will go hand-in-hand with partnerships. Many centers are keen to get involved and want to know how. Whereas a nonpolitical center such as Switzerland may seem ideal, with close contacts with WHO in Geneva, in practice many places could use their own resources to great benefit, whether public, international or private, together with funding from philanthropic agencies such as the Gates Foundation.

The establishment of Academic Centres of Tropical Surgery, mooted 20 years ago [18], has come of age. It is an urgent priority not just for the 2 billion people in the tropics and sub-tropics, but for the future of surgery in the West.

\section{References}

1. Ozgediz G, Dunbar P, Mock C et al (2009) Bridging the gap between public health and surgery: access to surgical care in lowand middle-income countries. Bull Am Coll Surg 94:14-20

2. WHO Global Initiative for Emergency and Essential Surgical Care. www.who.int/surgery/mission/GIEESC2005_Report. Accessed 1 July 2010

3. WHO Safe Surgery Saves Lives. www.who.int/patientsafety/ safesurgery/en. Accessed 1 July 2010

4. Watters AK, Bayley AC (1987) Training doctors and surgeons to meet the surgical needs of Africa. Br Med J 295:761-763

5. Ozgediz G, Galukande M, Mabweijano J et al (2008) The neglect of the global surgical workforce: experience and evidence from Uganda. World J Surg 32:1208-1215

6. Chu K, Rosseel P, Trelles M et al (2010) Surgeons without borders: a brief history of surgery at Médecins Sans Frontières. World J Surg 34:411-414

7. Nthumba PM (2010) "Blitz surgery": redefining surgical needs, training, and practice in sub-Saharan Africa. World J Surg 34: 433-437

8. Sani R, Nameoua B, Yahaya A et al (2009) The impact of launching surgery at the district level in Niger. World J Surg 33:2063-2068

9. Monjok E (2009) The neglect of the global surgical workforce: experience and evidence from Uganda (Letter). World J Surg 33:150-151

10. Welling D, Ryan JM, Burris DG et al (2010) Seven sins of humanitarian medicine. World J Surg 34:466-470

11. Meier D (2010) Opportunities and improvisations: a pediatric surgeon's suggestions for successful short-term surgical volunteer work in resource-poor areas. World J Surg 34:941-946

12. Meo G, Andreone D, De Bonis U et al (2007) Rural surgery in southern Sudan. World J Surg 30:495-504

13. Nordberg E, Mwobobia I, Muniu E (2002) Major and minor surgery output at district level in Kenya: review and issues in need of further research. Afr J Health Sci 9:17-25

14. Research out of Africa (2010) Lancet 375(9725):1496

15. Kasotakis G (2009) Requiem for the general surgeon. Bull Am Coll Surg 94:20-22

16. Hedges J, Ruscher KA, Chu K (2010) Is the generalist surgeon obsolete? Bull Am Coll Surg 95:24-26

17. King M, Bewes P, Cairns J et al (eds) (1990) Primary surgery, vols 1, 2. Oxford University Press, Oxford

18. Holcombe C (1990) The need for a Chair in Tropical Surgery. Br J Surg 77:3-4 